\title{
Editorial: Historical continuum, mimetic fissures
}

The call for this special issue of Organised Sound, 'Sound Art and Music: historical continuum and mimetic fissures', focused on the precept that sound art and music evolve in a shared world and that the joint navigation of this common terrain would allow new creative approaches to be taken by artists, curators, theorists and participants (listeners). In response to this conception, this journal issue sought to invite said artists, curators, writers, and listeners to present a current interpretation and assessment of such approaches, showing their plurality and revealing the themes and concerns along which further discussions could develop.

The suggestion in the background of this endeavour was that the current prominence of sound art has been aided by its relationship to visual arts practice and its discourse, but that even as this visual affiliation has promoted sound art's recognition, making it more visible, it has also obstructed the discussion of its sonic materiality and processes and has neglected its musical heritage and those aspects of its practice that recall that history. Consequently, much contemporary sonic output is not appreciated and approached as a critical response to previous and concurrent musical works but is considered mainly in relation to the concerns of visual practice and theory. As a result, contemporary sonic works are not theorised through a musical sensibility - understood in relation to a musical expression and musical questions - nor have they the influence to critique and advance traditional musical practices and our critical engagement with them. Rather, what is highlighted in much current sound arts discourse is the conceptual and contextual concerns it shares with visual arts history.

The absence of a musical sensibility and heritage in the discussion of sonic works, and the lack of a jointly elaborated critical framework of sound art and music have consequences for how we perform, install, curate, listen to and write about sonic works. It influences and determines our listening strategies and defines our references as well as the way sonic materiality is understood, discussed and practised. And while it was never the intention of this call for contributions to outdo or ignore the contextual and conceptual criticality of a visual discourse, a focus on music and musicality, its histories and practices, make alternative modes of thinking available that can augment and contribute not only to the discussion of sonic works but, ultimately, also to the discourse of visual arts.

It is in this context that this issue of Organised Sound invited a discussion of the relationship between sound art and music, to focus on the relevance of this relationship and to debate how it might impact on the way we listen to and critique sonic works; how we practise sound art and music; and ultimately maybe even how we engage in the visual arts. The submissions we received have in part responded to our precept, appeasing our desire for interpretations and strategies, but they have also added further complexities, critiques and questions to this relationship which, as the reader will see, do not get us to a conclusion but engage its fluidity and plurality through listening and soundmaking towards further discussions.

The motivation to call for responses to this theme, and to edit them into what we believe is a plural and complex mixture of texts, arose from both editors' long-standing engagement in sound and sonic practices in both camps: music and sound art. We were inspired and intrigued by their persistent separation: the politics of their disciplinary boundaries; the aesthetic expectations that fund and maintain them; as well as the practicalities of their transgressions, creating fissures as well as continuations. In a post-postmodern world there seems conceptually at least very little need to construct and maintain boundaries between any discipline. This fact makes the persistence and institutional ratification of this particular boundary ever more intriguing and relevant: hinting at greater ideological, social and cultural separations of which sound art and music are but a symptom, but which their joint discussion might well help reveal and debate.

The editors understand that there are well-guarded professional interests invested in their separation. We also accept that there is an economy of disciplines that protects the autonomy of production and discourse as well as funding, pedagogic frameworks and the institutional authority necessary to continue certain modes of working that might well erode in a less guarded context. And that there is, beside the more intentional separation, also no doubt an institutional lethargy and convenience that maintain the status quo on the level of criticism, curation and pedagogy, upholding a current legitimacy and value that practice, critical musical and sound art practice, by necessity ignores and transcends, but which discourse swiftly realigns. To make an open call for these discussions, in a peerreviewed journal, grants authority to the critique of those interests by offering another economy, another institution: that of writing and scholarship, to retrace borders, merging interests and laying the foundation to practise a continuation and perform territorial fissures. 
As much as the responses to the call demonstrate a complex diversity of opinions, motivations and aims, so too the editors' views on and investments in the theme do not represent a simple and homogenised position. For Salomé Voegelin, one of the crucial debating points is terminology, not as a label but as a naming, as a calling into a frame of reference and production that consequently establishes the frame of interpretation and valuation.

Visual arts is still called visual arts when in many ways it could just be called arts since a good number of its manifestations deal with non-visual elements and create a multisensory demand. The 'visual' in visual arts, does not or does not only pertain to a physiologically visual engagement, the act of seeing the work, or the presence of a visual object, the fact of the seen, but relates to the ideology of visuality, the selfcertainty of seeing, its immediacy and sociohistorical location that is confirmed in the visual emphasis of Western language and philosophy. The term 'visual' then has ceased to be a material reference and instead describes a belief, a history and a discourse, born in the notion of objectivity, hierarchical subject-object relations and the language that frames its evaluation through the certainty of the noun. But we have yet to read a polemic for its abolition.

By contrast the word sound in sound arts experiences constant scrutiny and even ridicule: a theoretical pointing at the outsiders, the esoterics, the worshippers of materiality, embodiment and essence, who want to create a separate sphere of influence for works that often, and apparently paradoxically so, use visual and other sensorial inputs. When the 'sound' in sound arts, just as the 'visual' in visual arts, does not necessarily point to a material essentialism or an ephemeral (non-object) condition, but frames a sensibility, a belief and an attitude towards the work, that creates a consequent shift in historical references, with regard to the subject-object relationship at the root of Western philosophical thought, and in terms of linguistic considerations that in sound are based on the uncertain activity of the verb.

Between sound and visual as prefixes to the arts we have two different belief systems that do not necessarily map onto music in expected ways. Ideologically, music is often not about sound at all but fulfils visual ideals: the mathematical absolute of the monochord and the ideality of harmonic development, much easier comprehended in the visual score than in the sonic temporality of performance, reflects a visual ideology. However there are musical practices: improvisation, some electroacoustic practices, etc. that abandon historical objectivity and ideality to produce a more sonic worldview not apprehendable in a visual frame but practising the fleeting invisibility of its own processes.

For Salomé then, on the back of such distinctions, skirmishes of beliefs and radicality take place: philosophical, sensorial, material as well as personal battles of influence and authority are fought out to determine what words mean and how they position our perception and sense of value between music and the arts.

Most of the articles in this issue include deliberations of terms and definitions in their engagement between sound art and music. Their careful distinctions are developed through the foci on pedagogy, listening behaviours, compositional strategies as well as by considering temporal and spatial relations and technological advances. These considerations expose sound not simply as a material essence or process but also as a cultural, conceptual and ideological force.

Throughout this selection of texts, music meets sound arts between ideology and materiality, between belief and thing: defining and defying histories and conventions, to redraw boundaries of practice and discourse. The ideological aspects of their meeting emphasises the extra-artistic importance of its discussion: it is not about beauty, sentiment, rationality or aesthetic concepts, but about how we come to understand these terms and ourselves taking part in their definition and valuation, producing a politics of discipline, professionalisation and theory. The material aspects of their encounter meanwhile forge new ideas about practice, engagement and perception: evoking a sonic aesthetic and sociality and questioning the notion of (visual) objects and spaces as portents of identity and relationality.

Read through this collocation of material practice and ideological determination, these articles do not just contribute to the discourse of sound art and music but transcend those boundaries to provide relevant intuitions for a wider debate on materialism, spatial practices, techno-aesthetic readings, pedagogy as well as for notions of physicality and subjectivity. In this sense these texts do not present an inward-looking collection, focused only on genre and discipline, material and medium, but create a larger debate on language, belonging, identity and practice through the juxtaposition of music and sound.

Thomas Gardner complements and develops this emphasis on terminology and ideology through a focus on the idea of an 'inclusive disjunction'. Motivating his involvement in this journal was the hope that people would respond to the most unsettling part of its call, which concerns the ambivalent position inherent in both valuing the separation of the territories of sound art and music and, the same time, appreciating their togetherness. The disturbing nature of this request arises not only from the binary that it asks us to engage with, but also from the sense that there may be an implicit colonialisation at stake, either by sound art or by music. The term 'inclusive disjunction' is gratefully borrowed from Allen S. Weiss and is used here to indicate the situation in which sound art and music can occur simultaneously, together, but that it remains possible to distinguish between their operations. 
The desire for rich and detailed responses to this double-edged question has been met, and the articles offered here present a wide variety of powerfully argued strategies and insights which will be the subject of much further discussion.

Additional hopes, some of which have not been met directly, but which have been implicitly discussed, include that, in the light of the radical theorisation of sound, there could be an equally radical theorisation of musical processes and structures. These propositions would accept the critique of the autonomous work proposed by scholars such as Lydia Goehr and Carl Dahlhaus, but revive the exploration of what is stereotypically understood as musical substance, in particular pitch and rhythm. Underlying these familiar parameters is the apparent incommensurability of hierarchical (the overtone series in pitch, the ageing process in our experience of time) and democratic (equality of distance between pitches, metronomic time) forms of measurement, leading to an inherent diversity in musical actions and objects. That these most elementary of musical measurements are, on the surface, incompatible with each other, suggests that the problems of the 'inclusive disjunction', which exists around sound art and music, are already present in the substance of musical activity.

Many of the articles implicitly refer back to these questions of measurement - for example, by discussing intonation - through the extension of musical senses of time into installation art, or via a revival of Trevor Wishart's critique of lattice-based thinking. However, the degree to which the articulation of these paradoxical forms of musical measurement should be followed through and felt to permeate our experience, from resonance and entrainment onwards, remains a profound question. Henry Purcell's song "If music be the food of love, play on" articulates this very directly

your eyes, your mien, your tongue declare that you are music ev'rywhere.

And this leads to Thomas's final hope, which was that the articles would explore the ways in which the musical experience of the world, a form of creation myth, might be conceived to have a boundary or limit. To put it another way, the hope was that the texts would address and maybe answer the question 'In what ways could the unfolding territory of music give way to something else?'

Again, this issue's articles provide a variety of compelling answers to this - some focusing on the deconstruction of the binary distinction between sound and music through a third term (sculpture, embodied cognition, radio and recording, computer software), others began from one side and show ways in which it can be developed towards the other (acousmatic sound moved towards instrumental performance, or musical form extended into gallery or city space), yet others offer a critique of one of the terms (e.g. an investigation of the pedagogical role played by language in early sound art), whilst others, finally, hint at a philosophical position in which the anthropocentric distinction between music and sound is no longer at issue.

At least three themes emerged regularly in thinking through these boundary issues. The first concerns language, and the extent to which musical articulation has a distance from linguistic articulation, and its implicit reverse: the degree to which sound, which may not be musical, draws on linguistic articulation for its recognition or valuation, an issue that meets Salomé's focus on terminology not as set definitions but as calling in to play.

The second concerns mimesis, and the interchange that occurs not only between the mimetic forms of representation offered by recording technology, but also how these touch on the reflexive mimetic interactions between musicians (the rhythmic entrainment of one musician with another).

The third concerns electronic media, and the degree to which our listening, articulation and grasp of sound has become dependent on or is determined by this technology.

The order of articles as they are printed here is but one, temporarily settled on, combination of many possible permutations, which each would be as relevant as another, highlighting particular commonalities, contradictions, developments and arguments and foregrounding different narratives on the relationship between sound art and music. So please dear reader feel free to read them in any order you wish, as no doubt, in the liminal spaces between each text lays a silence of reflection from which new insights emerge that are not as yet present in the writing.

\section{THE ISSUE'S CONTENTS}

The first article, Peter Batchelor's 'Acousmatic Approaches to the Construction of Image and Space in Sound Art', focuses on the relationship between acousmatic music's conventions of installation and presentation and its influence on listening, definition and pedagogy. Batchelor's article grounds the difference between sound art and music in their different heritage: one in acousmatic music and one in the plastic arts, imputing tradition and technology, context and historical circumstance, for their disciplinary boundaries. His discussion brings with it notions of pedagogy, as a cultural and educational preparedness for listening; and pitches compositional intentions against audience perceptions.

His text suggests that the fixed listener position of the concert hall becomes a historical and metaphorical place of fixity: fixing the work in conventions and traditions and fixing acousmatic practices conceptually and ideologically. According to him acousmatic, 
reduced, listening, does not hear a different present but reduces listening to the past, an attitude for which he blames the perceived need for coherence and against which he develops his own critical and practical challenge: through a case study of his own work GRIDs, he comes to suggest that the key to a different practice might lie in the reducedness not of listening but of the loudspeaker as a technological device and as an aesthetic form.

As an opener, Peter Batchelor prepares the ground for many discussions to come. He introduces pedagogy, a cultural preparedness for listening, as an important theme between sound art and music, later developed in different ways by Adam Tinkle via a focus on Cage. He also draws our awareness to technology as an aesthetic and ideological device that defines the different ways sound is processed and displayed in both sound art and music, introducing issues considered with some particularity by Damien Charrieras and François Mouillot in their article 'Getting Out of the Black Box', as well as in Gerald Fiebig's text on recordability. Batchelor's focus on the arrangement, use and abuse of speakers, as well as their significance within sound art work as sculptural devices, introduces space and spatiality, terms investigated also by Adam Basanta in his effort of 'Extending Musical Form Outwards in Space and Time', and considered in relation to sensoriality by Frederico Macedo's in his investigation into the 'Five meanings of space in music and sound art'. While the sculptural nature of this sonic and technological spatiality is further developed in Vadim Keylin's explicit engagement in music and sound sculpture, the focus on the speaker as object of listening is in a more implicit way continued in the writing of Marie Højland and Morton Riis, who develop a wavefront aesthetic to propose an objectorientated ontology for sound art, and also by Martyn Hudson and Tim Shaw, who, through similar discursive references, consider sound art and music as ensembles of objects.

Batchelor's inclusion on the distinction between real-life sound, field recording material and an acousmatic treatment thereof links remarkably to the debate staged by James O'Callaghan on mimesis and instrumentality and also makes an interesting connection to Maria Garcia Sanchez's sound grammar. The observed influences of these texts on each other is naturally hindsight, the privilege of the editors. They are neither causal, chronological and hierarchical nor consequent, but simply serendipitous. The breadth of Batchelor's text impresses the many connections not, however, the exhaustion of their issues and methods, nor does it judge the value and validity of each subsequently printed writing. And so Rob Casey's 'Developing a Phenomenological Approach to Music Notation' brings to acousmatic works a closer focus on embodiment and corporeality that does not so much follow as elaborate and match Batchelor's reach.
Rob Casey's article draws on insights gained from a theory of embodied cognition to critique phenomenological or idealist perspectives on sound, and focuses particularly on a new understanding of the score, which might otherwise be identified as an 'intractable obstacle' to vibrant sensory experience. He argues that a score can function not only as a text to be read, but can also participate in the multimodal perception of force structures which underpin our everyday experience. Thus, according to Casey, a musician's sensorimotor performance and the visual force-structures in a score share a common and reciprocal base and allow a 'fluid, co-dependent chain of causation' to operate between semiotic and phenomenological domains, something which is demonstrated persuasively in his own work I Remember It Was Yellow, which serves him as a case study.

Adam Basanta's article, 'Extending Musical Form Outwards in Space and Time: Compositional strategies in sound art and audiovisual installations', however, offers an insightful re-mapping of a quality seen to reside in music, namely its temporal form, to a quality seen in installations, namely the spatial presentation. In this process the first-person perspective can be completely altered, from the central immersion of the listener in the time of the work to the central immersion of the listener in the space of the work. However, rather than aiming at a complete reconfiguration of the listening position from a temporal to a spatial orientation, Basanta argues that the temporal structuring of the installation remains a decisive creative factor, and goes on to detail ways in which this plays a vital part in a variety of installations, including key examples from his own work 'room dynamics'.

The re-mapping conducted by Basanta, working from a temporal to a spatial listening focus, finds an echo in James O'Callaghan's writing that seeks to bring a technological perspective, the production of recorded sound, to conventional instrumentation, thus essentially 're-mapping' technological sensibilities and actualities through acoustic practice.

In 'Mimetic Instrumental Resynthesis', O'Callaghan examines a very literal return of the material effects of media technology to the musical field, exploring the ways in which recorded sound can be re-transcribed for acoustic instruments. His text traces some of the practices associated with this, including Helmut Lachenmann's instrumental musique concrète, the Spectral compositions of Gérard Grisey and Tristan Murail, the theories of Francois Bernard Mâche as well as prescient examples from his own work.

Throughout his article, the tension between instrumental music and media technology gives rise to a variety of vivid concerns which are explored in the text, touching, for example, on the ontology of notation and its relation to recorded sound; reflecting on the relation between stylised and hyper-real aesthetics of 
representation; or considering the bodily concreteness of instrumental performance compared to Schaeffer's concrete recorded sound.

O'Callaghan's turn towards the acoustic, the instrument, its body, scoring and physical reality finds an interesting complement in Vadim Keylin's article 'Corporeality of Music and Sound Sculpture'. Keylin places the invention and practice of sound sculpture at an awkward historical moment when postmodernism had done away with the modernist categories and thus the idea of sound sculpture as an autonomous genre seemed out of step with what was going on at the time. However, reconsidered through a contemporary lens, this outsiderness of sound sculpture, its emphasis on craft, materiality and the corporeal, offers a radical critique of modernist works' malleability into a neoliberal economy. The artisanship and physicality, on the part of the composer and the audience/user, foregrounded by sound sculpture, questions notions of abstraction, the absolute, and the idea of music proper, and promotes the way to a different understanding and reaction to sound.

Keylin develops his writing through the main example of Harry Partch, which allows him to compare sound art with carpentry, and enables him to address postwar abstraction and infuse it with a discussion on emotions, physicality, equivalence and the democratisation of the musical process. In his search for a middle ground between abstraction and physicality, Keylin focuses on sound sculpture's relationship to the score, and how it re-evaluates the relationship between the composer, player and his instrument. $\mathrm{He}$ also considers the design and construction aspects of the sculptures and how they reframe the technology of sound-making not as a means to a sonic end but as a means to a form.

This debate on technology as form, process and outcome is also central in the text by Damien Charrieras and François Mouillot. Their article, 'Getting Out of the Black Box: Analogising the use of computers in electronic music and sound art', centres on the relation of the composer to the computer not as a black box, a meta-tool and quasi neutral device of production, but as an instrument, that stands as metaphor and metonymy of the human-machine relationship, opening it to new potentialities of production, experience and discussion. The authors present analogue music production as a process of conversion, where "the body of the musician is transduced through curbs of electrical energy transiting through her body'. Such physical, analogue, transduction is brought as concept and strategy into the digital realm to argue for an innovative technical ecology where the composer/ performer stands in a physical relationship with software and hardware 'instruments'.

Starting their survey from Max Mathews 1960s proposition of the computer as instrument, the authors work through various technological developments and artistic approaches, Dirty Electronics and Just Robots, among them, to articulate an analogue logic for digital machines: proposing physical computing as a shared practical attitude and useful fulcrum between sound art and music, which allows them to bring both practices together.

For Gerald Fiebig too it is technology, in particular the development of recording equipment and the reality and concept of recordability, that brings sound art and music into a comparative frame. His article discusses recordability as technology and also as instrumentality and as aesthetic shift. Via Trevor Wishart's notion of 'Sonic Art', Fiebig aims to break with what he considers to be a forced choice between sound art and music to 'formulate a comprehensive aesthetic of acoustic artworks - an aesthetic which [...] will have to take into account the fact that listening to acoustic artworks in our age always takes place within a horizon of recordability'. To achieve this more coherent vision, his article situates sound art simultaneously in several reference systems at once: galleryoriented sound art, electroacoustic music in the tradition of Pierre Schaeffer and radio work. From here he presents various contemporary approaches to the separation between music and sound art, notably Seth Kim-Cohen's focus on the non-cochlear, in order to eventually use the listening focus of radio art, as Ars Acoustica, to bring sound art, in its various manifestations, together with music, under one umbrella of recordable and listened to sounds.

Maria Garcia Sanchez's article 'A "Sound Grammar" for the City: The spatial and temporal dimension of Barber's concerts' engages the notion of technology and instrumentality, and thus the definition of sound art and music, in reference to the city: a human-made place that he/she inhabits with the mechanisms of his/ her production.

Llorenç Barber's transformation of the city into a monumental instrument grants her access to the urban environment as grammar, as language and as discursive strategy. For Sanchez, Barber's city concerts, which centre around the activation of bells, the most common sound mark in Western cities, have various complex consequences for the performer and the composer as well as the listener, to whom, according to Sanchez, in the end the concert belongs, since the indeterminacy of the urban environment transcends individuality in a collective concert.

Her article sets out a clearly structured account of the concept, processes and practicalities of the city concert genre, and illuminates many of its consequences for music, the citizens and the city heard. According to her account, the composition of the urban environment produces a city from its invisible relationships and presents a form of acoustic ecology: creating, implicitly and explicitly, a listening 
education - questioning the preconception of what a concert, what music but also what the city is - as well as revealing traditions and histories hidden in those invisible relationships.

Continuing on the theme of a 'sound grammar' with an explicit emphasis on pedagogy, Adam Tinkle's article 'Sound Pedagogy: Teaching listening since Cage' provides a robust and trenchant critique of the pedagogic use of language in early sound art practice, drawing attention to the double bind implicit in the use of verbal injunctions to assert sound's freedom. Tinkle uses an analytic framework that he calls 'sound pedagogy' to detail an unacknowledged dependency in Cage's listening revolution on linguistic articulation, and explores this with salient historical detail. This provides a curiously circular framing of the question, which underlies this call for articles, concerning the extent or limit of the territories of sound art and music. By suggesting that the ability to listen outside the structuring activities of music is underpinned by an unacknowledged reliance on the structuring powers of language, Tinkle outlines a world of unconscious co-dependency. His article concludes by suggesting that the unwinding of sound art's early deafness to its own linguistic usage is in progress, and that more conscious forms of articulation have been developing in recent practice, showing the promise of "plurally constructed cultures of listening ... that both require and generate literacy'.

Frederico Macedo's article 'Investigating Sound in Space: Five senses of space in music and sound art' pursues a literacy of post-1950s music as 'spatial music' or 'spatialised music', which, through its deliberate and structural use of space, can be compared to the development of sound art, as an art, identified through the German tradition, that is primarily concerned with the installation and sculpture of sonic material. Answering to what he perceives as inconsistencies in the use of spatial terms and their theorisation between sound art and music, Macedo's article sets out a topology of five different uses of space: metaphor, acoustic space, sound spatialisation, reference and location. The first category, metaphor, is staged as a preliminary and more abstract concept of perceptual experiences, while the remaining four are related to specific aspects of the materiality, treatment and perception of sound in space. All five categories are carefully defined and manage to produce an integrated and comparative framework to discuss sound art and music via their spatial concepts and properties.

Macedo's taxonomy offers an interesting framework for a new and different understanding of the relationship between sound art and music. It establishes useful references for their discussion and proposes an innovative method for cross-referencing. However, and in common with all taxonomical organisations, as much as what is listed and described is relevant and insightful, what remains outside his topology holds much intrigue too. And so, as he admits himself at the end of his article, the work is not 'exhaustive, and a broader application of the ideas suggested here will offer a rich and varied field for future research'.

Another new method of analysis and theorisation that also suggests and calls for future research is presented in Marie Højland and Morton Riis's text 'Wavefront Aesthetic: Attuning to a dark ecology'. The authors follow and develop the ideas of objectorientated ontology, and in particular the writings of Timothy Morton, to debate sound art as a collaborative effort between machine objects and human objects. This methodology is promoted to complement and add to the recently established theorisations of sound art and to bring a less human-centred perspective to the perception, description and analysis of sonic works. Their argument, which is focused on two different case studies of the authors' own works, demonstrates the application of ontology to sound by foregrounding the interactions of the instruments, the lights sensors, the speakers etc. in order to create not an anthropocentric spectacle but 'attunements between objects'. The stated aim of the article is to achieve a dark ecology of equivalence, creating coexistence and connection not only between and for humans but also between objects. The authors argue that this focus on attunement and collaboration also negates the disciplinary boundaries between sound art and music, which as interobjects attain equality in a flat ontology.

The final article, Martyn Hudson and Tim Shaw's piece 'Dead Logics and Worlds: Sound art, and sonorous objects', which draws on discursive references which are similar to the previous text, has slipped into a liminal space between the special theme of this issue and Organised Sound's role as publisher of scholarly articles more generally concerned with music and sound. It resides here, at the conclusion of a series of texts on the relationship between sound art and music, not because it offers less interesting and relevant insights and discussions, but because unlike the others, this text has in some respects moved beyond the tensions of this relationship and points more particularly and exclusively towards sound art.

By considering the sonorous object as something that stands 'behind the sensual object comprehensible to human observation', there is, according to Hudson and Shaw, the potential to link musical understandings of data with other technological or object-oriented understandings of 'data'. As examples the authors focus on the anthropologically informed reuse of the 'dead' materiality of the data in recorded sound. In this way they suggest a flexibility to move in and out of the frames of reference that give human agency a special place in musical constructions of data, to move into 
and out of the non-human agency, which they have begun to methodologically address through the idea of the sonorous object.

And while this last article, in its focus on sound art, falls out of the exact thematic of this journal issue, it seems apt to start reading the series of texts with Hudson and Shaw's reminder of the human agency of listening and reading, and its impact on any work and any interpretation thus produced, before moving on to peruse the articles in their fullness.

Salomé Voegelin (mail@salomevoegelin.net)

Thomas Gardner (123thomas.gardner@googlemail.com) 